\title{
Open-pit crawl dozers operating under northern climatic conditions
}

\author{
Ishkov A.M. \\ Mining Machinery Department \\ North-Eastern Federal University n.a. M.K. Ammosov \\ Yakutsk, Russia \\ gormashygu@mail.ru
}

\author{
Zedgenizov V.G. \\ Building and Road Machinery and Hydraulic Systems \\ Department, \\ Irkutsk National Research Technical University \\ Irkutsk, Russia \\ fai@istu.edu
}

\author{
Morozova A.I. \\ Mining Machinery Department, Mining Institute, \\ North-Eastern Federal University n.a. M.K. Ammosov \\ Yakutsk, Russia \\ yaunaa89@mail.ru
}

\begin{abstract}
Tough climatic conditions of the North impose special requirements for mining machines operating in that area. The article analyzes failures of Komatsu D-375A and Komatsu D-375A5 to assess the effects of operating conditions on reliability of their components and systems. Statistical analysis is used to compare performance characteristics of Komatsu D-375A and D-375A5. Correlation and regression analysis was applied to assess temperature effects on mining machinery operations. Experimental data were used to identify season dependent periodicity of failures. Performance analysis for machines operating in the Far North identified the dependence of machinery failures on operating temperatures. It was identified that a failure flow for basic components and systems of Komatsu increases from two to six times at low temperatures compared to the warm period of time.
\end{abstract}

Keywords - crawler dozer; failure; low temperatures; mounted equipment; distribution; correlation coefficient

\section{INTRODUCTION}

According to State Standard 16350-80, Yakutia is located in the zone of cold climatic conditions and characterized by large amplitudes of annual ambient temperatures. The difference of mean temperatures in July and January in the southern areas of Yakutia is $50^{\circ} \mathrm{C}$, in the northeastern ones - more than $60^{\circ} \mathrm{C}$. In winters, temperatures are extremely low due to clear sky, light winds and increased atmospheric transparency. The lowest temperatures in the Northern hemisphere are observed in Oimyakon and Verkhoyansk. The mean monthly temperature in January is $-50^{\circ} \mathrm{C}$, the minimum one is $-71^{\circ} \mathrm{C}$.

The rapid spring increase and the autumn decrease in mean daily temperatures are typical for the thermal regime of Yakutia. The warmest month is July. The mean ambient temperature in central and southern areas of Yakutia is $19^{\circ} \mathrm{C}$, the highest temperature is $38^{\circ} \mathrm{C}$.

Low winter and high summer temperatures are one of the features of the thermal regime of Yakutia (difference in absolute minimum and maximum temperatures is over $100^{\circ} \mathrm{C}$ ). The mean annual temperature is $-11^{\circ} \mathrm{C}$.

The relative air humidity varies over a wide range throughout the year. In cold periods, the relative air humidity varies only slightly and is $73-79 \%$, in summer it goes down to $45-50 \%$. Mean annual values of the absolute air humidity in central Yakutia are 4.2-4.8 mb. The lowest humidity is $0.1-0.3 \mathrm{mb}$ in January, the highest one is 12.5 $13.5 \mathrm{mb}$ in July.

Due to very low winter and high summer temperatures, large annual amplitudes (temperature differences for the warmest and coldest months and differences in absolute temperature minimum and maximum) are typical for the thermal regime of Yakutia.

Thus, Yakutia is second to none by winter and by annual temperature amplitudes in the Northern hemisphere.

The regions, similar in climatic indices, are:

- Northern European areas of Russia and Scandinavian North;

- Northern Asia and northern part of the North America;

- Central Yakutia and central part of Alaska;

Swamp areas of subarctic tundra of the North America and tundra zones and northern taiga subzones of Russia are the most difficult for vehicles to travel.

In general, severe winter climatic factors are more typical for the North of Russia than for the northern part of the North America, but due to lower air humidity, humans 
can relatively easy withstand those climatic conditions.

According to many researchers, the ambient temperature is a crucial climatic factor. Temperature drop decreases reliability of machines, systems, and components. In this case, one can observe several threshold temperature values.

Temperatures rising above zero cause formation and freezing of condensate water and moisture in components and assemblies, formation of blocks in pipes, freezing of cuffs to shafts and rods, ice expansion, and other damages. Those failures occur in temperate zones as well, but the number of zero-crossing days in cold zones is about 90 , while in temperate ones, it is equal to 70 days.

At a temperature of $-25^{\circ} \mathrm{C}$, failures occur due to the impact of low temperatures on operating characteristics of rubber and polymer parts. Rubber parts lose elasticity and become fragile. Depressurization of packing seals causes fluid, oil and air leakage. Cracks in rubber parts cause their failures, wire insulation damage, shorts and electrical equipment failures.

At a temperature of $-35^{\circ} \mathrm{C}$ or below, low temperatures influence metal parts, increase the number of fragile damages, especially of the parts used in the open air and subjected to dynamic loads.

Increased wear is one more crucial cause for low machinery reliability under cold climatic conditions. This failure is typical for transmission systems and engines. The ambient temperature influences the oil which ensures fluid friction of related parts, carries the heat away, removes wear products from clearances, and protects the surface from corrosion. Low temperatures deteriorate lubricating properties due to increased viscosity. They also deteriorate oil pumping abilities. Oil does not flow to the friction surfaces, and semi-dry or even dry friction occurs, and resinous substances are formed. The nature of wear failures is similar to the one under moderate climatic conditions, but extremely low temperatures increase their intensity.

Low temperatures make it difficult to maintain machines during inter-shift periods, at weekends and on holidays. High costs of machines require idle time reduction. Severe climatic conditions and three-shift working demand higher standards for operators in the North - for their physical, psychological and professional training. Blizzard conditions, snowstorms, ice storms, and bad visibility make working conditions harder, increase hazard risks, reduce the speed of vehicles. Along with factors deteriorating working conditions of drivers (snow, ice storms, poor visibility, etc.), low ambient temperatures require improvement of heat insulation and comfort of vehicle cabs (structural characteristics of cars, quality of metals, rubber products, combustibles and lubricants).

In cold climatic zones, earthmovers and rippers mounted on open pit crawler dozers are used at all mining stages. Excavated frozen ground falls under grades V-VII exhibiting an increased ice content. Significant volumes of those operations cause application of open pit crawl dozers throughout the year. $35 \%$ of all operations are performed in winter.

Geological factors of open pit crawl dozer operations result in significant increase (up to $30 \%$ ) in loading on their components and assemblies. Therefore, climatic conditions cause special requirements for structural and maintenance materials employed for manufacturing open pit crawler dozers.

Low temperatures deteriorate engine startability, maintenance and structural materials properties, seal elements, and decrease thermal regimes of assemblies and systems of crawl dozers. These factors decrease component durability by $25-30 \%$. Intensive increase in the number of failures occurs at ductile to brittle phase transition temperatures of metals of the weld and weld zone.

Failures resulted from low temperatures and damages of parts are typical for northern regions due to increased dynamic factors occurring when excavating permafrost. Therefore, failures of attachments are very common in the North.

Mining operating conditions, long distances form power supply sources, and vast mining practice determined application of crawl dozers at open pit mines.

\section{RESULT AND DISCUSSION}

At present, crawl dozers are widely used in Yakutia due to their universal characteristics. They can perform a wide range of development, stripping, reclamation and auxiliary operations. KomatsuD-375A and its modernized version Komatsu D-375A5 are widely applied in mining industry.

The article aims at comparing performance properties of Komatsu D-375A and Komatsu D-375A5 under real operating conditions. To assess the effects of operating conditions on reliability of components and systems of the crawl dozer, occurring failures were analyzed. The authors examined 13 Komatsu D-375A crawl dozers and 13 Komatsu D-375A5 crawl dozers. Statistical data were gathered at the Neryungri mine operated by Ltd. Yakut Ugol and the Mayat mine operated by JSC Almazy Anabara. Statistical data on failures of components and assemblies were gathered from maintenance department registries.

A database integrated into the databank was created for Komatsu D-375A and Komatsu D-375A5 performance analysis. The version of the databank in Microsoft Office Access makes it possible to interact with modern operating systems, study records on dependences between objects of the database, and provides support for the database. It is used to establish the procedure for ascending or descending sorting. A more flexible menu of the databank makes it easier to enter new information, examine records and draw reports.

Databank users can scan, enter and edit data. The databank also allows pattern match searching, printing and screening of failure statistics reports (after data filtering). 
TABLE I. NUMBER OF FAILURES BAY SISTEMS KOMATSU D-375A5 AND D-375A

\begin{tabular}{|c|c|c|c|}
\hline No & System & D-375A5 & D-375A \\
\hline 1 & Final drive & 3 & 12 \\
\hline 2 & Water pump & 2 & 12 \\
\hline 3 & Blade cylinder & 10 & 2 \\
\hline 4 & Dozer blade tilt cylinder & 6 & 2 \\
\hline 5 & Ripper cylinder & 9 & 0 \\
\hline 6 & Carriage pillar & 4 & 23 \\
\hline 7 & Carriage fingers of the truck & 7 & 0 \\
\hline 8 & Support rollers & 2 & 28 \\
\hline 9 & Power steering pump & 7 & 0 \\
\hline 10 & Blade & 22 & 25 \\
\hline 11 & $\begin{array}{l}\text { Support rollers for the crowns of the } \\
\text { driving sprocket }\end{array}$ & 2 & 9 \\
\hline 12 & Radiator & 8 & 27 \\
\hline 13 & Truck frame & 11 & 4 \\
\hline 14 & Tractor frame & 5 & 1 \\
\hline 15 & Fan drive belt & 1 & 9 \\
\hline 16 & Generator drive belt & 2 & 8 \\
\hline 17 & Ripper shank & 23 & 1 \\
\hline 18 & Fuel pump & 1 & 7 \\
\hline 19 & Hydraulic system & 27 & 24 \\
\hline 20 & Transmission system & 10 & 16 \\
\hline 21 & Electric wiring & 10 & 2 \\
\hline 22 & Equalizer bar & 0 & 21 \\
\hline 23 & Cylinder beam & 0 & 5 \\
\hline 24 & $\begin{array}{l}\text { Crowns of the driving sprocket } \\
\text { (left, right) }\end{array}$ & 0 & 5 \\
\hline 25 & Cylinder block head & 0 & 18 \\
\hline 26 & Panhard rod & 0 & 4 \\
\hline 27 & Track idler (left, right ) & 0 & 12 \\
\hline 28 & Turbocharger & 0 & 13 \\
\hline 29 & Track roller seal & 0 & 5 \\
\hline 30 & Turboline of the control mechanism & 0 & 6 \\
\hline 31 & Total amount of failures & 172 & 301 \\
\hline
\end{tabular}

Implementation of the method increased failure statistics efficiency, made it possible to interact with existing operating systems, scan records by selected data, and form reports on machines, parts and systems.

Data in the databank are tabulated by months of the operating time in order to assess the effects of climatic temperatures on Komatsu performance (see Table 1).

Table 1 shows that Komatsu D-375A crawl dozers have 301 failures, while Komatsu D-375A5 - 172 failures for the same operating period.

For Komatsu 375A5, the following failures were identified: blade system -22 , blade cylinder - 10 , truck frame - 11 , crawl dozer frame - 5, radiator - 8, ripper shank 23 , hydraulic system -27 , transmission system - 10 , electric wiring - 10, power steering pump - 7. It speaks for the incomplete follow-up of the components. There are no failures of equalizer bars, cylinder blocks, crowns of the driving sprocket, cylinder heads, panhard rods, track idlers, turbochargers, track roller seal, turbolines of the control mechanism.

Komatsu D-375A has a greater number of failures: final drive -12 , water pump - 12 , carriage pillar -23 , support rollers -28 , blade system - 25 , radiator - 27 , hydraulic system -24 , transmission system -16 , equalizer bar -21 , cylinder block head -18 , track idler -12 , turbocharger -13 .
Table 1 shows that systems with the largest number of failures are:

- $\quad$ hydraulic system
a) D-375A5 -27
b) D-375A - 24

- $\quad$ blade system
a) D-375A5 -22
b) $\mathrm{D}-375 \mathrm{~A}-25$

Failures due to low temperatures and damages of the components and assemblies of the crawl dozer are also caused by increased dynamic factors occurring when excavating permafrost. Therefore, failures of attachments are very common in the North.

Reliability analysis identified the following drawbacks of operations under for cold climatic conditions:

- Insufficient durability and cold endurance of some materials applied, and increased sensitivity to stress concentrators;

- Low quality of steel structures welding;

- Insufficient performance of rubber products;

- Insufficient maintainability of crawl dozers.

They increase expenses for rock processing in winter.

Components wear is devastating. Over 4000 tons of metal are lost in dumps. The most destructive type of wear is abrasion of the metal surface. That type of wear decreases the lives of ground contact parts.

Figure 1 shows a distribution of the number of failures of Komatsu D-375A by months. As can be seen, most failures occur in autumn due to intensive preparation works for the winter period.

Figure 2 shows a distribution of the number of failures of Komatsu D-375A5 by months. As can be seen, most failures occur in winter.

Let us compare four Komatsu crawl dozers used at the Mayat mine (D-375A) and Neryungri mine (D-375A5) for a more accurate analysis.

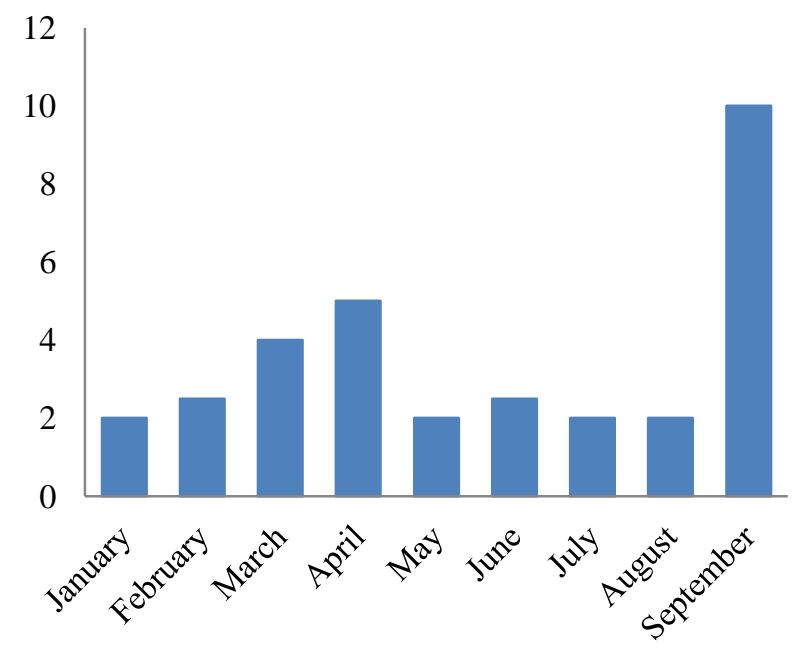

Fig.1. Distribution of the number of failures of D375A by months 


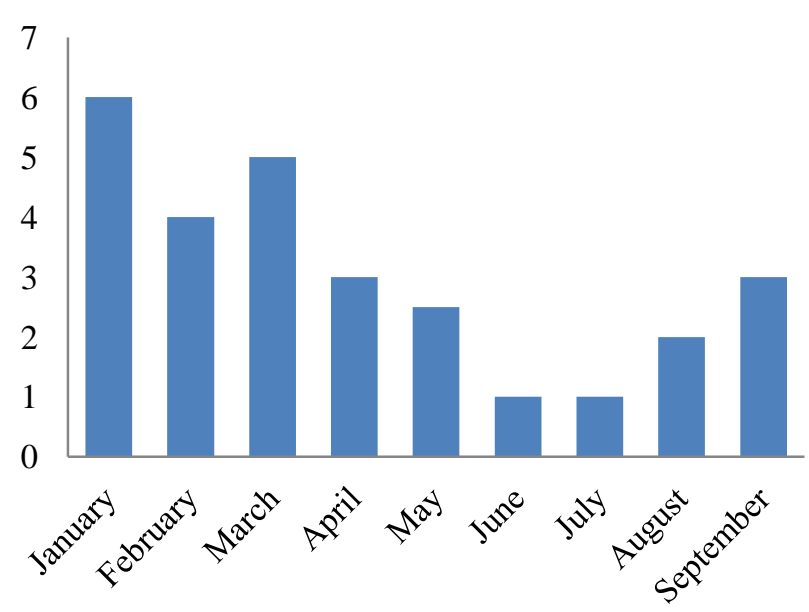

Fig.2. Distribution of the number of failures of D375A5 by months

Analysis of a number of factors (humidity, wind velocity, insolation duration, temperature, precipitation) showed that the most crucial one is ambient temperatures. Other natural and climatic factors either have close relations with temperatures or have no significant impact on crawl dozer reliability. It simplified calculations and interpretation of results obtained as far as a linear regression equation (1) can be used to assess the effect of natural and climatic factors on crawl dozer reliability:

$$
Y=B_{o}+B_{i} X
$$

where $\mathrm{X}$ - factor-argument, independent random variable (ambient temperature); $\mathrm{Y}-$ factor-function, dependent random variable; $B_{o}$ and $B_{i}$ - coefficients of a regression equation.

Identification of a relationship type involves calculation of regression coefficients $B_{o}$ and $B_{i}$ which are determined by (2):

$$
\left\{\begin{array}{c}
\sum_{i=1}^{n} Y_{i}-n B_{0}-B_{1} \sum_{i=1}^{n} X_{i}=0 \\
\sum_{i=1}^{n} X_{i} Y_{i}-B_{i} \sum_{i=1}^{n} X_{i}-B_{1} \sum_{i=1}^{n} X_{i}^{2}=0
\end{array}\right.
$$

Those equations with two variables $\mathrm{B}_{\mathrm{o}}$ and $\mathrm{B}_{\mathrm{i}}$ are used to calculate regression coefficients based on experience data.

The relationship between the number of failures or idle time to eliminate the consequences of failures and ambient temperatures can be calculated with the correlation coefficient formula (3):

$$
r=\frac{n \sum_{i=1}^{n} X_{i} Y_{i}-\left(\sum_{i=1}^{n} X_{i}\right)\left(\sum_{i=1}^{n} Y_{i}\right)}{\sqrt{n \sum_{i=1}^{n} X_{i}^{2}-\left(\sum_{i=1}^{n} X_{i}\right)^{2}} \sqrt{n \sum_{i=1}^{n} Y_{i}^{2}-\left(\sum_{i=1}^{n} Y_{i}\right)^{2}}}
$$

If $\mathrm{r}=1$, then the relationship is strong (functional); if $r=0.85$, then the relationship is strong; if $r=0.55$, then the relationship is moderate; if $r=0.30$, then the relationship is weak; if $r$ is negative, then the relationship is reverse.

To determine the strength of the relationship, we use (4)

$$
Y_{i}-Y_{x i}=Y_{i}-Y-\left(Y_{x i}-Y\right)
$$

where $Y_{x i}$ is the component of the dependent variable determined by variability of the independent variable; $Y_{i}-Y_{x i}$ is the component of the dependent variable determined by some other unaccounted factors (including model selection errors); $Y$ is the mean value of the dependent variable.

Taking the square root of both members of equations and summing up, one gets:

$$
\mathcal{Q}=\mathcal{Q}_{p}-\mathcal{Q}_{o}
$$

where $\mathcal{Q}$ is the sum of squares with respect to the mean value; $\mathcal{Q}_{p}$ is the sum of squares due to regression; $\mathcal{Q}_{\mathrm{o}}$ is the residual sum of squares.

Then the strength of the relationship between $\mathrm{X}$ and $\mathrm{Y}$ is:

$$
\rho=\sqrt{\frac{Q_{p}}{Q}}=\sqrt{1-\frac{Q_{o}}{Q}}
$$

This value describes the strength of the functional relationship.

The analysis showed that linear relationships between the number of failures or idle time to eliminate the consequences of failures and ambient temperatures comply with statistical data.

Based on statistics processing results, the authors identified distribution functions of a correlation coefficient for the blade system and hydraulic system (see Table 2).

Figure 3 shows the distribution of the number of failures of the hydraulic system of Komatsu D-375A5 by temperature values. The correlation coefficient for failures of the hydraulic system of Komatsu D- 375A5 is equal to 0.6

Figure 4 shows the distribution of the number of failures of the hydraulic system of Komatsu D-375A5A by temperature values. The correlation coefficient for failures of the hydraulic system of Komatsu D-375A5 is equal to 0.8 
TABLE II.

FAILURES CAUSED BY CLIMATIC CONDITIONS FOR KOMATSU D-375A5 AND D-375A

\begin{tabular}{|l|c|}
\hline \multicolumn{1}{|c|}{ System } & $\begin{array}{c}\text { Correlation } \\
\text { coefficient }\end{array}$ \\
\hline Hydraulic system line of Komatsu D-375A & -0.8 \\
\hline Hydraulic system line of Komatsu D-375A5 & -0.6 \\
\hline Blade system of Komatsu D-375A & 0.05 \\
\hline Blade system of Komatsu D- 375A5 & -0.36 \\
\hline
\end{tabular}

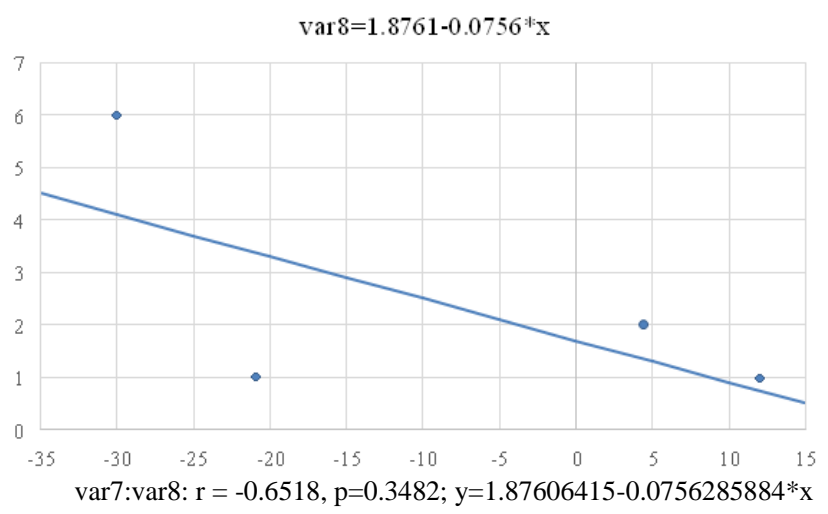

Fig.3. Distribution of the number of failures of the hydraulic system of Komatsu D-375A5

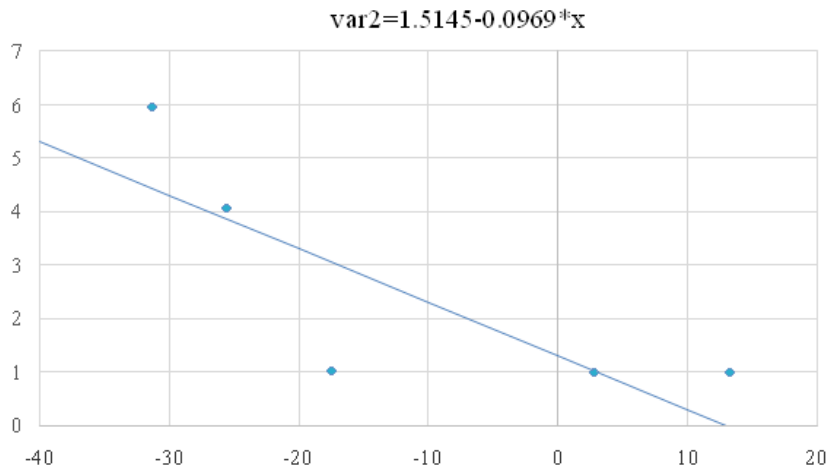

$\operatorname{var} 1: \operatorname{var} 2: \mathrm{r}=-0.8209, \mathrm{p}=0.0885 ; \mathrm{y}=1.51446607-0.0969226723^{*} \mathrm{x}$

Fig.4. Distribution of the number of failures of the hydraulic system of Komatsu D-375A

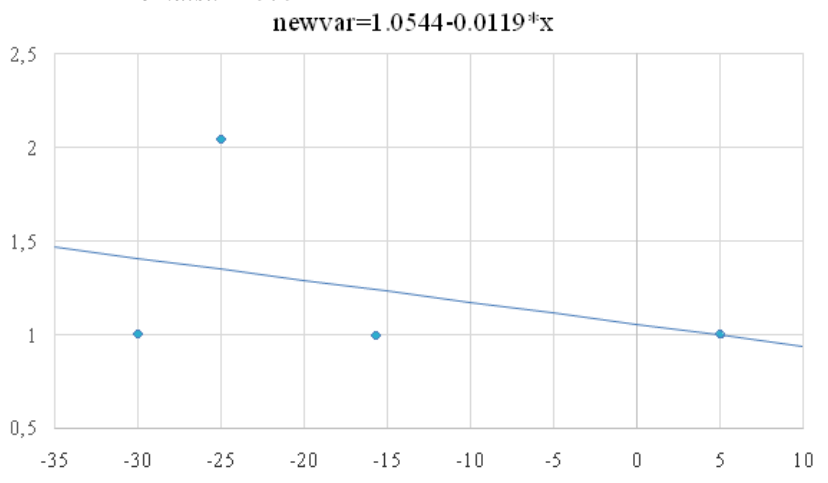

var10:newvar: $\mathrm{r}=-0.3665, \mathrm{p}=0.6335 ; \mathrm{y}=1.05439331-0.0118549512 * \mathrm{x}$

Fig.5. Distribution of the number of failures of the blade system (Komatsu D-375A5)

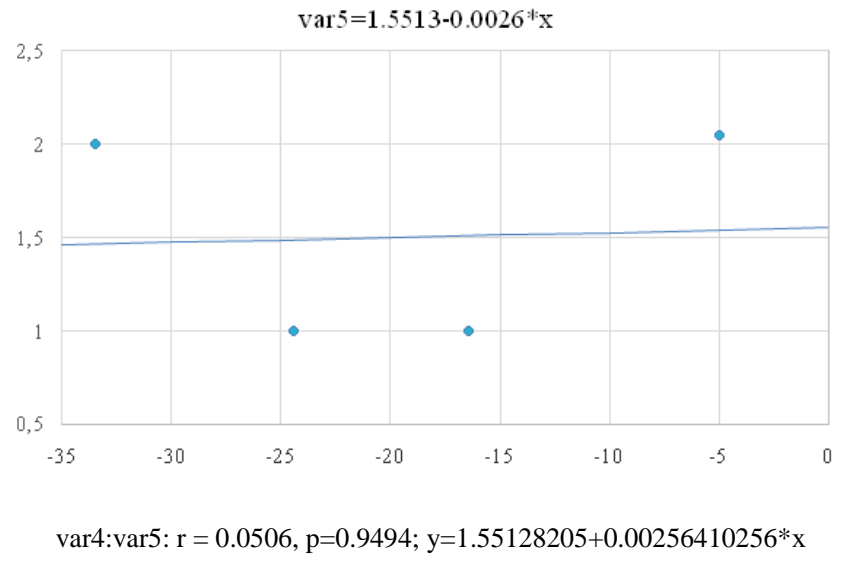

Fig.6. Distribution of the number of failures of the blade system (Komatsu D-375A)

Figures 5 and 6 show distributions of the number of failures of the blade systems of Komatsu D-375A5 and Komatsu D-375A by temperatures.

\section{III. \\ CONCLUSIONS}

1. Based on the statistical analysis, performance properties of components and assemblies of Komatsu D375A and Komatsu D-375A5 were compared.

2. It was identified that operating reliability of the tractor systems exhibited dependence on the climatic factors. Modernized version of KomatsuD-375A5 has half the number of failures (172) of Komatsu D-375A (301), while the number of failures of the main assemblies did not change and new types of failures were identified which speaks for design deficiency.

3. The analysis identified Komatsu D-375A and D375A5 component and assemblies limiting their performance. To enhance performance of open pit crawl dozers, maintenance departments have to prepare reliability limiting parts in advance.

4. Long-term experience of using mining crawl dozers shows that autumn-winter and winter-spring stripping operations increase the number of failures of mechanical equipment, hydraulic systems, fuel system and electrical equipment. Besides, frequent damages of metal structures of machines occur. To achieve efficiency in use of resources, the volume of crawl dozer works should be reduced in autumn-winter periods and performed in spring-summer ones.

5. The method for determining the crawl dozer performance is of practical use.

\section{References}

[1] A.A. Vodolazkiy, "Increase in maintainability of crawl dozers at northern open pit mines»" (abstract of the candidate's degree in Engineering thesis), Irkutsk, 2004.

[2] V.D. Glevob, "Increase in durability and costs reduction for crawl dozers", Bulletin of Pskov State University. Economics. Law. Management, vol. 5, pp. 166-168, 2014.

[3] A.M. Ishkov, M.A. Vikulov Mining machinery operation in the Far North (manual), Moscow, Forum, Infa-M, 2015, p. 144. 
[4] A.M. Ishkov, M.A. Kuzminov, G.Y. Zudov Theory and practice of machine reliability under northern conditions. (monograph), Yakutsk, Izd-vo SO RAN, 2004, p. 313.

[5] V.S. Kvaginidze, V.F. Pentorv, V.B. Koretskiy, Mining equipment operation, Moscow, Gornaya kniga, 2009, p. 587.

[6] V.S. Kvaginidze, "Crawl dozer maintenance and repair at low negative temperatures" / Ed. by V.S. Kvaginidze, A.A. Vodolazskiy, N.N. Chupeikina, Mining information and analytical engineering journal, vol. 3, 2006.

[7] E.V. Kurilov, D.I. Troshin, "Transportation features of the blade", Mehanizatsiya stroitelstva, vol. 12, 2013.

[8] D.E. Makhno, S.Y. Krasnoshtanov, A.M. Ishkov, M.A. Vikulov Mining methods and machines at northern mines, (monograph), Irkutsk, Izd-vo IRNITU, 2015, 216 p.

[9] "Komatsu D375A-5", Building and road machines, vol. 12, pp. 58-59, 2015.

[10] R.Y. Poderni, H.R. Koelsh, "Adaptation of hydraulic shovels for Arctic temperature of Yakutia", Mine planning and equipment selection conference 2010, pp. 729-730, December 2010. Fremantle, W. Australia, 2010 [Proceedings of Mining Planning and Equipment Selection (MPES) Conference, p. 749, 2010].

[11] 11. M.I. Schadov, K. Yu. Anistratov, A.V. Fedorov, "The method of forming open-pit mining equipment fleet at a functioning venture", Moscow: Gornaya Promyshlennost, vol. 5, pp. 10-13, 2009.

[12] A.P. Van-Van-E, G.F. Sklyarova, N.A. Lavrik, "Scientific principles of formation of ore mining regions of the Far Eastern Federal District”, Eurasian Mining, vol.1, pp.3-7, 2014.

[13] G.G. Vinokurov, S.P. Yakovleva, A.K. Kychkin, M.I. Vasil'eva, N.F. Struchkov, M.V. Fedorov, "Structural changes in wear of the rock cutting element of a bulldozer operating under the northern conditions", Russian metallurgy (Metals), vol. 5, pp. 431-436, 2009.

[14] W. Wang, Sh. Huang, X. Wu, Q. Ma, "Calculation and Management for Mining Loss and Dilution under 3D Visualization Technical Condition", Software Engineering and Applications, vol. 4, pp. 329334, 2011.

[15] C. Wasson, "Mining Mountains" Pit \& Quarry, pp. 56-59, March 2015. 